\title{
ESTUDO DA TÉCNICA POST-STIRRING E MECANISMOS ENVOLVIDOS
}

\author{
Amilton Carlos Pinheiro Cardoso Filho' \\ Hugo Filipe Parreiras Gonçalves ${ }^{2}$ \\ Carlos André Ruy Carneiro ${ }^{3}$ \\ Túlio Carvalho da Silva Araújo ${ }^{4}$
}

\section{Resumo}

São apresentados os resultados do estudo da técnica post-stirring nos convertedores da Aciaria 2 da Usiminas Ipatinga. Os testes consistiram basicamente na rinsagem do banho por meio da injeção de argônio após o fim de sopro de oxigênio, utilizando-se ventaneiras localizadas no fundo do convertedor, por um período de tempo pré-determinado. Os resultados mostram que a prática do post-stirring permite redução média de 250 ppm no teor de oxigênio e 30 ppm no teor de fósforo dissolvido no aço. Além disso, são propostos mecanismos de reação para a remoção do oxigênio e do fósforo. Portanto, esta técnica é uma prática importante para a melhoria do processo. Além de reduzir os níveis de fósforo, verifica-se um grande potencial de economia no consumo de material desoxidante, devido à redução nos níveis de oxidação, com reflexos positivos em termos de custos e limpidez do aço.

Palavras-chave: Post-stirring; Convertedor LD; Oxigênio.

\section{STUDY OF POST-STIRRING TECHNIQUE AND INVOLVED MECHANISMS}

\begin{abstract}
This paper presents the results of the application of the post-stirring technique in the BOF of Usiminas, in Ipatinga. The tests consisted basically in the rinsing of the metal bath with argon injection after finished the oxygen blowing, through tuyeres placed in the bottom of the converters, for a pre-established period. The results showed that the poststirring technique allowed a mean reduction of $250 \mathrm{ppm}$ in the oxygen content and $30 \mathrm{ppm}$ in the phosphorus content of the steel. It is possible to conclude that post-stirring technique is effective in the process optimization. Besides reducing the phosphorus content in the steel, it is verified a huge opportunity to reduce the consumption of deoxidizing materials, due to a decrease in the oxygen level, reducing costs and improving the steel cleanness.
\end{abstract}

Key words: Post-stirring; Basic oxygen furnace; Oxygen.

\section{INTRODUÇÃO}

Em convertedores com sopro pelo topo, conhecidos como processo convencional, a agitação do banho é promovida essencialmente pela energia de impacto do jato de oxigênio colidindo com o banho metálico e pelo borbulhamento do gás de $\mathrm{CO}$ gerado na descarburação. No entanto, em determinadas regiões, existem "zonas mortas", onde há deficiência de agitação e misturamento.
A instalação de ventaneiras nas solas de convertedores para injeção de gases incorporou ao processo convencional as vantagens de agitação oferecidas pelos processos onde o sopro de oxigênio ocorre pelo fundo, corrigindo as deficiências de misturamento. $A$ ascensão do gás injetado em direção à superfície do banho líquido incrementa sua recirculação, garantindo homogeneidade de composição e temperatura em todo o banho metálico. A Figura I apresenta um desenho esquemático do processo de sopro combinado em convertedor LD.

\footnotetext{
'Membro da ABM, Engenheiro Metalurgista, Gerência Geral de Pesquisa e Inovação, Usiminas, Ipatinga, MG; Rua Filipinas, III, apto. I05, Bairro Cariru, CEP 35 I60-340, Ipatinga, MG, Brasil.E-mail: amilton.cardoso@usiminas.com

${ }^{2}$ Membro da ABM, Engenheiro Metalurgista, Gerência Geral de Pesquisa e Inovação, Usiminas, Ipatinga, MG; Rua Filipinas, III , apto. I05, Bairro Cariru, CEP35 I60-340, Ipatinga, MG, Brasil.E-mail: hugo.goncalves@usiminas.com ${ }^{3}$ Engenheiro Metalurgista, Gerência Geral de Pesquisa e Inovação, Usiminas, Ipatinga, MG, Rua Princesa Isabel, I59, Bairro Bom Retiro, CEP35 160-00, Ipatinga, MG, Brasil. E-mail: carlos.carneiro@usiminas.com ${ }^{4}$ Membro da ABM, Engenheiro de Materiais, Gerência de Convertedores da Usina de Ipatinga, Usiminas, Rua D, I45, Condomínio Aldeia do Lago, Coronel Fabriciano, CEP 35I7I-505, Ipatinga, MG, Brasil. E-mail: tulio.araujo@usiminas.com
} 


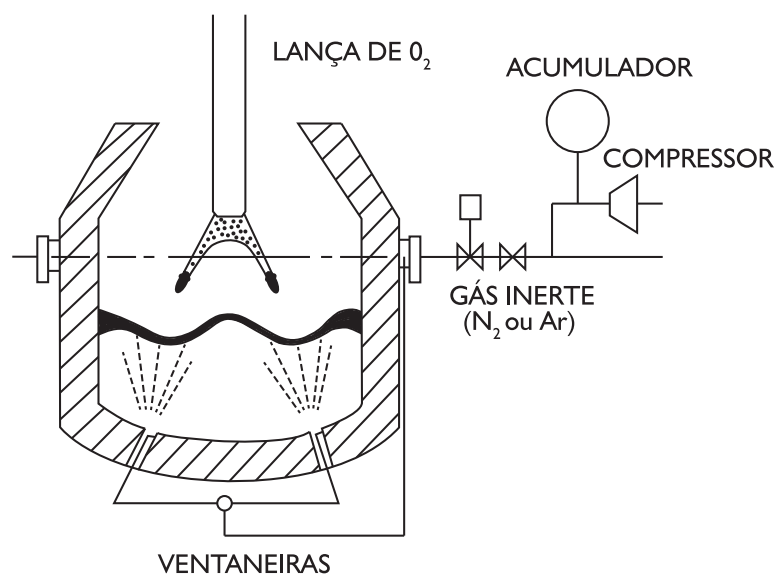

Figura I. Desenho esquemático de um convertedor evidenciando o sopro combinado - LD-KGC.(1)

Nos processos de refino do aço, depois de terminado o sopro, permanece um desequilíbrio entre o aço e a escória. A escória formada ao fim de sopro possui altos teores de $\mathrm{FeO}$ e $\mathrm{CaO}$ dissolvidos, características favoráveis à remoção do fósforo. No entanto, devido à queda na taxa de descarburação nos momentos finais do sopro e, consequentemente, à baixa força de agitação promovida pelo gás $\mathrm{CO}$ formado, a condição da escória fim de sopro não é devidamente aproveitada na desfosforação.(2)

A técnica post-stirring, ou rinsagem/agitação, após o sopro consiste na injeção de gás inerte pelas ventaneiras por um determinado período de tempo depois de terminado o sopro de oxigênio. Essa técnica possibilita utilizar plenamente as características da escória, fazendo com que o sistema aço-escória se aproxime das condições de equilíbrio. $O$ gás injetado através das ventaneiras na sola do convertedor provoca uma agitação do banho, intensificando a interação metal-escória através de uma constante renovação da superfície de contato entre essas fases, aumentando a extensão das reações de refino.

Vários benefícios metalúrgicos da técnica post-stirring são descritos na literatura, ${ }^{(3,4)}$ tais como: aumento da partição de fósforo; redução no nível de oxidação do banho; redução do teor de $\mathrm{FeO}$ da escória, com consequente aumento do rendimento metálico e redução do desgaste dos refratários, por ataque químico. Neste contexto, o objetivo deste estudo é avaliar os benefícios metalúrgicos decorrentes da prática post-stirring nos convertedores da Usiminas Ipatinga e comparar os resultados obtidos com os registrados na literatura.

\section{MATERIAL E MÉTODOS}

As experiências de post-stirring foram realizadas em 35 corridas, nos convertedores 4 e 5 da Aciaria 2 da Usiminas Ipatinga. Esses convertedores possuem capacidade de 180 toneladas e apresentam oito ventaneiras cada, conforme o esquema apresentado na Figura 2.

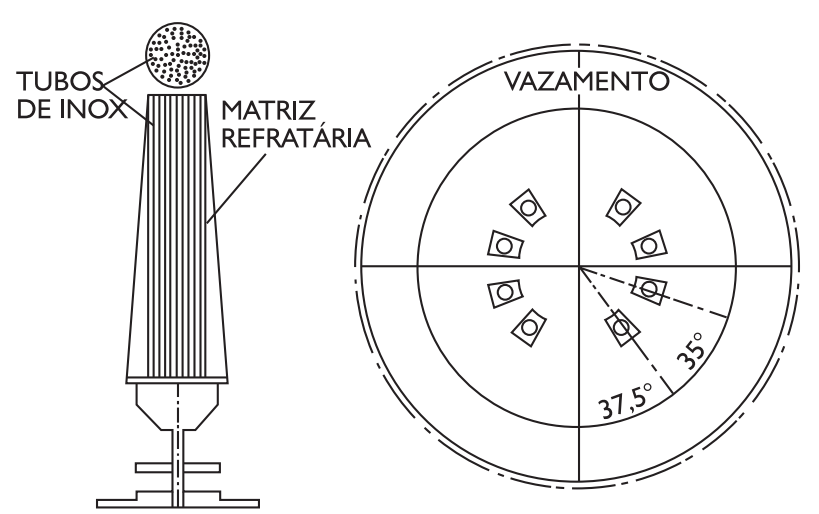

Figura 2. Desenho esquemático de uma ventaneira, e sua distribuição no fundo do convertedor. ${ }^{(1)}$

As ventaneiras são constituídas de uma matriz de refratário de $\mathrm{MgO}$ com tubos de aço inoxidável no interior, por onde ocorre a injeção dos gases. Suas dimensões são $130 \mathrm{~mm}$ de diâmetro, na face em contato com o banho líquido, e $1.086 \mathrm{~mm}$ de altura.

O gás (nitrogênio ou argônio) é injetado nas oito ventaneiras através de uma única linha, controlada por uma válvula, um medidor de pressão e um medidor de vazão. As vazões mínimas e máximas permissíveis no sistema são $60 \mathrm{Nm}^{3} / \mathrm{h}$ e $800 \mathrm{Nm}^{3} / \mathrm{h}$, respectivamente.

Os testes de post-stirring foram realizados conforme as etapas descritas a seguir:

- I a etapa: terminado o sopro de oxigênio, foi retirada uma amostra de aço, do tipo pirulito, e medido o nível de oxidação e a temperatura do banho, utilizando-se a sublança com sensor de oxigênio;

- $2^{\mathrm{a}}$ etapa: realizou-se a injeção de argônio através das ventaneiras a uma vazão de $100 \mathrm{Nm}^{3} / \mathrm{h}$ a

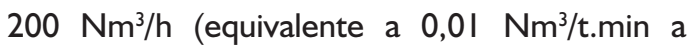
$0,02 \mathrm{Nm}^{3} / \mathrm{t}$.min) por um período de 2 minutos;

- $3^{\mathrm{a}}$ etapa: após o término da injeção de gás, foi recolhida uma nova amostra de aço e medida a oxidação e temperatura do banho.

As amostras de aço foram analisadas em laboratório químico pela técnica de espectrometria de raios $X$. Os resultados obtidos foram analisados utilizando ferramentas estatísticas.

\section{RESULTADOS}

\section{I Remoção de Oxigênio Livre e Carbono}

Os teores de oxigênio livre no aço, antes e após o post-stirring, são apresentados na Figura 3 na forma de boxplot. 


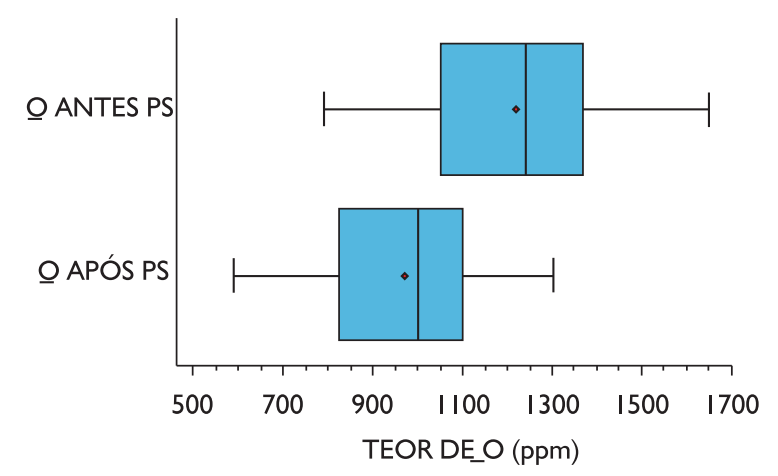

Figura 3. Teores de oxigênio dissolvido no aço antes e após o poststirring.

Observa-se, na Figura 3, uma dispersão dos resultados devido às diferentes características das corridas. Contudo, o teste de comparação das médias confirma a variação significativa do teor de oxigênio com a prática post-stirring. $O$ teor de oxigênio livre do banho ao fim de sopro variou entre 800 ppm e 1.650 ppm. Após a injeção de argônio, o teor é reduzido para a faixa de 600 ppm a I.300 ppm.

A Tabela I apresenta os teores médios de oxigênio livre no aço, antes e após a injeção de gás pelo fundo, bem como as temperaturas médias.

Tabela I. Valores médios de temperatura e oxigênio livre aferidos no aço antes e após o post-stirring

\begin{tabular}{ccccc}
\hline & $\begin{array}{c}\mathbf{T} \text { antes } \\
\mathbf{P S}\left({ }^{\circ} \mathbf{C}\right)\end{array}$ & $\begin{array}{c}\mathbf{O} \text { antes } \\
\mathbf{P S}(\mathbf{p p m})\end{array}$ & $\begin{array}{c}\mathbf{T} \text { após PS } \\
\left({ }^{\circ} \mathbf{C}\right)\end{array}$ & $\begin{array}{c}\mathbf{O} \text { após PS } \\
(\mathbf{p p m})\end{array}$ \\
\hline Média & 1.666 & 1.220 & 1.654 & 970 \\
\hline
\end{tabular}

A redução do teor de oxigênio livre no banho líquido, calculada pela diferença entre os teores de oxigênio antes e após a injeção de argônio, apresenta média e desvio padrão de 250 ppm e 178 ppm, respectivamente, podendo atingir valores de até $576 \mathrm{ppm}$.

A redução do nível de oxidação do aço durante o post-stirring também foi objeto de estudo de Rose e Becker. ${ }^{(4)}$ Conforme apresentado na Figura 4, para aços com teores de oxigênio de 875 ppm após o fim de sopro, verifica-se uma redução de 350 ppm, em média, durante um período de rinsagem de 100 segundos. Quando este período é extrapolado para 300 segundos, a redução chega a $475 \mathrm{ppm}$ de oxigênio dissolvido. Ainda nesta mesma figura, pode-se observar que $\circ$ aumento de oxigênio dissolvido no aço ocorre de maneira acentuada nos últimos segundos do sopro de oxigênio (aproximadamente $95 \%$ do tempo de sopro).

Verifica-se uma correlação entre a redução do nível de oxigênio no aço e o seu teor logo após o fim de sopro, conforme apresentado na Figura 5, comprovando que quanto maior for o grau de oxidação do aço no fim de sopro, maior será a redução do seu teor de oxigênio durante o período de post-stirring.

Correlação similar é observada por Bruckhaus e Lachmund, ${ }^{(3)}$ mas com uma menor dispersão dos dados, conforme apresentado na Figura 6, onde fica evidente a correlação linear entre a quantidade de oxigênio removida e o teor de oxigênio do aço ao fim de sopro.

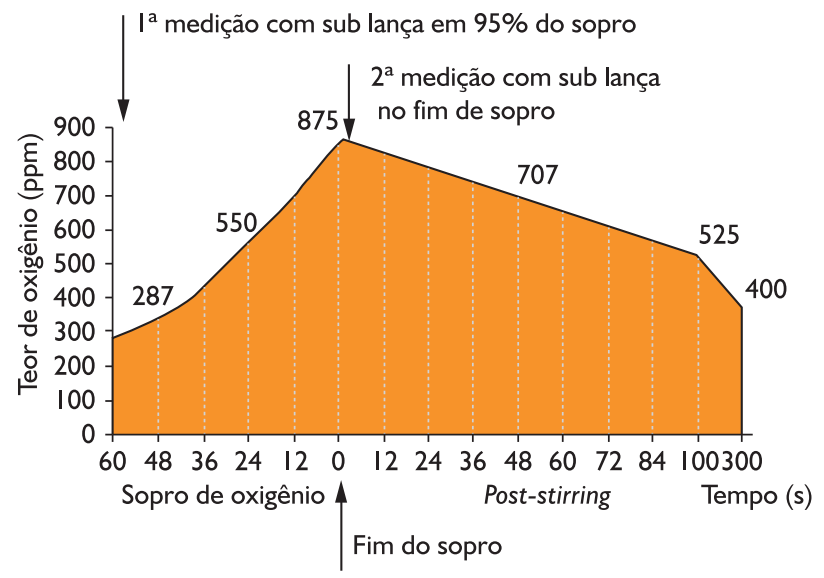

Figura 4. Teor de oxigênio em função do tempo de post-stirring. ${ }^{(4)}$

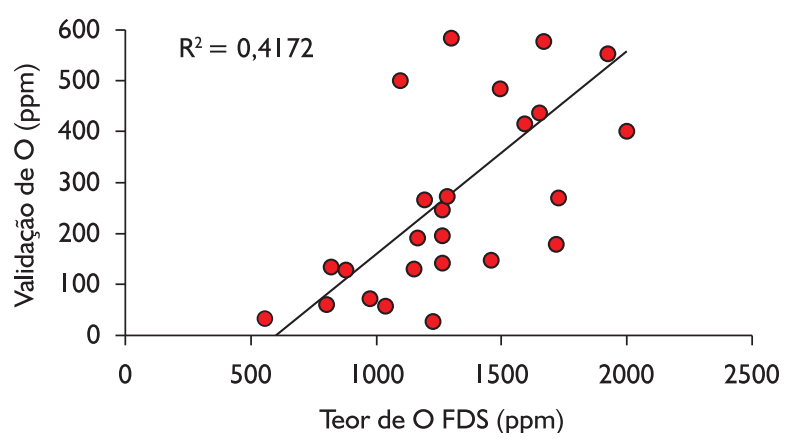

Figura 5. Correlação entre variação de oxigênio e teor de oxigênio ao fim de sopro.

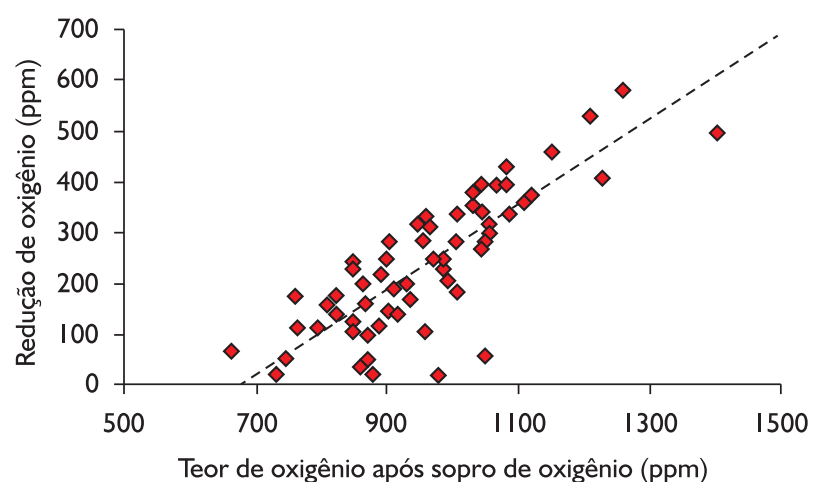

Figura 6. Quantidade de oxigênio removido durante post-stirring em função do teor de oxigênio fim de sopro. ${ }^{(3)}$ 
Durante a agitação do banho, ocorre perda de temperatura do aço líquido. Nos experimentos, a queda média observada foi de $12^{\circ} \mathrm{C}$. Guy, Grosejan e Le Maire ${ }^{(2)}$ também verificaram perdas de temperatura da ordem de $10^{\circ} \mathrm{C}$, para tempos de agitação em torno de 2 minutos. No entanto, relatam que essa seria praticamente a mesma perda que se tem com o banho estático. Afinal, o volume de gás injetado não chega a ser elevado devido ao curto tempo de injeção.

Em relação ao teor de carbono, observa-se, na Tabela 2, que os teores deste elemento no aço, antes e depois do post-stirring, apresentam baixa variação.

Embora a redução média de carbono tenha sido muito baixa, é importante destacar que seu teor ao final do sopro de oxigênio (\% C antes PS) já estava muito baixo. Provavelmente, se o teor de carbono estivesse mais elevado, as reduções teriam se elevado, a exemplo dos resultados de Rose e Becker, ${ }^{(4)}$ cuja redução média foi de 70 ppm de carbono, para tempos similares de injeção de argônio.

Tabela 2. Teores médios de carbono no aço, antes e após o poststirring, redução média de carbono e os respectivos desvios

\begin{tabular}{cccc}
\hline & $\begin{array}{c}\mathbf{C} \text { antes PS } \\
(\%)\end{array}$ & $\begin{array}{c}\mathbf{C} \text { após PS } \\
(\%)\end{array}$ & $\begin{array}{c}\Delta \mathbf{C} \\
(\%)\end{array}$ \\
\hline Média & 0,0315 & 0,0289 & 0,0026 \\
Desvio & 0,0119 & 0,0119 & 0,0020 \\
\hline
\end{tabular}

\section{I.I Mecanismo de remoção do oxigênio livre}

Guy, Grosejan e Le Maire ${ }^{(2)}$ propõem um mecanismo para explicar a redução de carbono e oxigênio durante $\circ$ post-stirring. Segundo eles, as bolhas do gás injetado criam sítios (interface gás-metal) para reação de descarburação (Equação l):

$$
\underline{\mathrm{C}}+\underline{\mathrm{O}}=\mathrm{CO}_{(\mathrm{g})}
$$

As bolhas de argônio também contribuem para a redução da pressão parcial do $\mathrm{CO}$, favorecendo sua formação. O CO formado é eliminado do banho juntamente com o gás inerte. Além disso, o carbono do banho também pode ser oxidado pelo $\mathrm{FeO}$ presente na escória, ${ }^{(4)}$ como representado pela Equação 2. A injeção de gás, neste caso, favorece a renovação da camada de metal em contato com a escória, ou seja:

$$
\mathrm{FeO}_{(1)}+\underline{\mathrm{C}}=\mathrm{Fe}_{(\mathrm{l})}+\mathrm{CO}_{(\mathrm{g})}
$$

Embora este mecanismo explique bem a remoção de carbono, a remoção de oxigênio não fica clara. Por meio de um balanço de massa usando a quantidade de oxigênio livre removido do aço (Tabela I), e considerando a relação estequiométrica da Equação I, é possível afirmar que a quantidade de carbono que deveria ter sido removida vai muito além da real removida (Tabela 2). Este fato induz à idéia de que o oxigênio esteja sendo removido através de outro mecanismo.

Com o intuito de complementar a explicação descrita por Guy, Grosejan e Le Maire,(2) propõe-se o seguinte mecanismo: a injeção de argônio gera bolhas que ascendem pelo banho em direção à superfície. Essas bolhas são envolvidas por uma camada estagnada de aço, denominada camada limite. Como a concentração de oxigênio no interior da bolha é nula, surge um potencial químico entre a fase metálica e o gás, que favorece a movimentação de oxigênio para o interior da bolha, com conseqüente formação de $\mathrm{O}_{2}$, segundo explicitado pela Equação 3:

$$
2 \underline{0}=\mathrm{O}_{2(\mathrm{~g})} \quad \Delta \mathrm{G}^{\circ}=56.000=1,38 \mathrm{~T}
$$

A análise termodinâmica mostra que a formação do $\mathrm{O}_{2}$ é espontânea para pressões parciais de $\mathrm{O}_{2}$ infinitamente pequenas (Equação 4):

$$
\Delta \mathrm{G}=28.000+0,69 \mathrm{~T}+\mathrm{RT} \ln (\mathrm{Q})
$$

onde (Equação 5):

$$
\mathrm{Q}=\frac{\left(\mathrm{PO}_{2}\right)}{(\mathrm{HO})^{2}}
$$

Como no interior da bolha de argônio a pressão parcial de $\mathrm{O}_{2}\left(\mathrm{PO}_{2}\right)$ é próxima de zero, o coeficiente $\mathrm{Q}$ torna-se extremamente pequeno. Consequentemente, a energia livre de Gibbs é negativa, mostrando que a reação de formação de $\mathrm{O}_{2}$ é espontânea nas condições de fabricação do aço.

As etapas envolvidas na reação são:

- $I^{a}$ etapa: movimentação do oxigênio dissolvido do seio do banho até a camada limite na bolha (convecção);

- $2^{a}$ etapa: difusão do oxigênio dissolvido através da camada limite;

- $3^{a}$ etapa: adsorção do átomo de oxigênio nos sítios ativos da superfície da bolha de argônio;

- $4^{a}$ etapa: combinação dos átomos de oxigênio para formação do gás $\mathrm{O}_{2}$; e

- $5^{a}$ etapa: desorção da molécula de oxigênio para o interior da bolha e sua subsequente eliminação do banho.

Como o oxigênio é um elemento tensoativo e as condições termodinâmicas são favoráveis à formação da molécula de $\mathrm{O}_{2}$, o mecanismo proposto explica a remoção de uma quantidade maior de oxigênio em relação à estequiométrica na reação com o carbono.

\subsection{Remoção de Fósforo}

Os teores de fósforo das amostras de aço, antes e após o período de post-stirring, são apresentados na Figura 7, na forma de boxplot. 


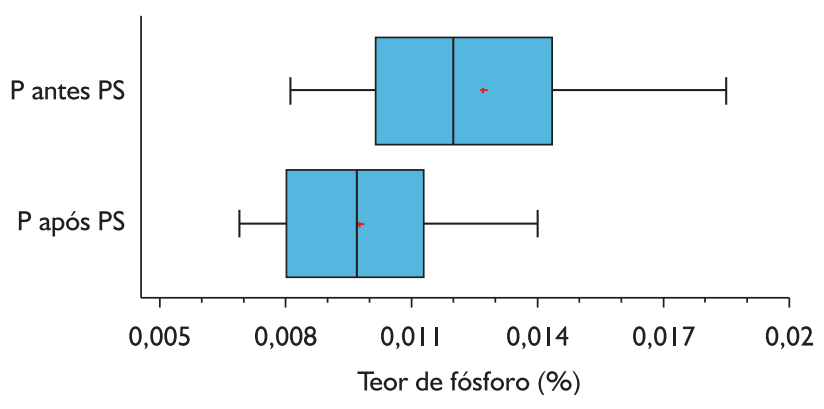

Figura 7. Teores de fósforo no aço antes e após o post-stirring.

Conforme apresentado na Figura 7, ocorreu uma diminuição global do teor de fósforo e uma redução considerável na dispersão dos resultados após o post-stirring. Os resultados de análises estatísticas indicam diferença entre médias dos teores de fósforo, antes e após a realização do post-stirring, com $95 \%$ de significância. Nas amostras de aço correspondentes ao fim de sopro (antes do post-stirring), o teor de fósforo médio é de 0,013\% (130 ppm), com desvio padrão de 0,003\% (30 ppm), enquanto que, para as amostras de aço após a injeção de gás, estes valores são de $0,010 \%$ e $0,002 \%$ (100 ppm e $20 \mathrm{ppm}$ ), respectivamente.

A redução média de fósforo é de $30 \mathrm{ppm}$, podendo chegar a 55 ppm. Embora pareça um valor baixo, é importante ressaltar que o teor de fósforo médio ao final do sopro de oxigênio estava muito baixo. Quando se analisa em termos de percentual de redução, entende-se que a rinsagem após o sopro propicia uma redução de até $35 \%$ do teor de fósforo no aço, ou seja, permite uma redução considerável deste elemento. Estes resultados estão de acordo com a literatura pertinente. (2-4) $^{(2)}$

Estudos realizados por Rose e Becker ${ }^{(4)}$ mostraram que a prática do post-stirring é responsável por uma redução no teor de fósforo em até 40 ppm. Guy, Grosejan e Le Maire ${ }^{(2)}$ obtêm resultados mais substanciais, atingindo reduções de até 100 ppm.

Os referidos autores ${ }^{(2)}$ mencionam ainda que reduções de 100 ppm ocorrem nos casos em que o teor de fósforo no aço, logo após o fim de sopro, é mais elevado (entre $0,025 \%$ e $0,035 \%$ ).

$\mathrm{Na}$ Figura 8, é apresentado um gráfico que correlaciona os teores de fósforo do aço antes e após a injeção de gás.

Conforme apresentado na Figura 8, os teores de fósforo, antes e após o post-stirring, podem ser correlacionados (Equação 6):

$$
P_{\text {após PS }}=0,7796 \times \% P_{\text {antes PS }}+4 \times 10^{-5}
$$

onde:

$P_{a p o ́ s}$ Ps $=$ teor de fósforo após o post-stirring (\%),

$P_{\text {antes Ps }}^{\text {após }}=$ teor de fósforo antes do post-stirring (\%).

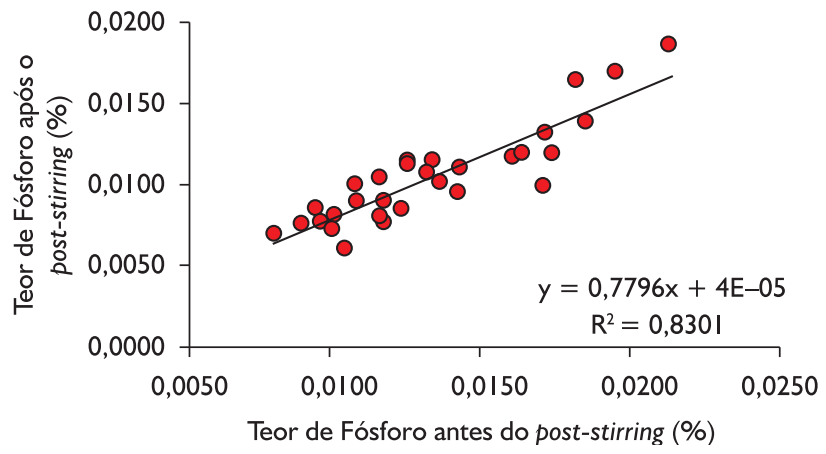

Figura 8. Correlação entre teor de fósforo do aço antes e após o período de post-stirring.

A Equação 6 pode ser utilizada como uma ferramenta auxiliar para definição da necessidade de ressopro devido ao alto teor de fósforo. Dependendo do teor de fósforo ao final do sopro a própria rinsagem poderia reduzi-lo até o nível desejado, tornando o ressopro desnecessário. Neste caso, a prática do post-stirring reduziriam a necessidade do ressopro.

\subsection{Mecanismo de remoção do fósforo}

O mecanismo envolvido na desfosforação durante o post-stirring pode ser explicado pelas seguintes etapas propostas:

- I a etapa: o fósforo dissolvido no banho é transportado até a interface metal/escória por convecção devido à movimentação do banho;

- $2^{\mathrm{a}}$ etapa: após a difusão do fósforo, através da camada limite na interface, ele é oxidado pelo $\mathrm{FeO}$ da escória, formando o pentóxido de fósforo $\left(\mathrm{P}_{2} \mathrm{O}_{5}\right)$; e

- $3^{\mathrm{a}}$ etapa: $\circ \mathrm{P}_{2} \mathrm{O}_{5}$ é fixado na escória devido à formação de um composto estável com o $\mathrm{CaO}$ dissolvido.

A prática do post-stirring tende a favorecer as duas primeiras etapas do mecanismo de desfosforação, pois a agitação gerada aumenta a renovação da interface metal/ escória e reduz a espessura da camada limite.

\section{CONCLUSÃO}

Por meio de uma análise teórica, é possível concluir que, no final do sopro de oxigênio, o metal e a escória encontram-se fora do equilíbrio termodinâmico. A injeção de gás inerte pelo fundo do convertedor após o sopro promove a renovação da interface metal/escória, contribuindo para que ambas as fases se aproximem do estado de equilíbrio.

Com base nos resultados dos experimentos, conclui-se que a prática do post-stirring proporciona redução média de 250 ppm no teor de oxigênio livre do aço, podendo alcançar 576 ppm. Isto representa uma 
redução média de $0,28 \mathrm{~kg}$ de alumínio/tonelada de aço, podendo chegar a $0,68 \mathrm{~kg} / \mathrm{t}$. Além disso, essa prática contribui efetivamente para melhoria do nível de limpidez do aço.

A rinsagem após o sopro ainda possibilita uma ligeira redução nos teores de carbono e fósforo (médias de $26 \mathrm{ppm}$ e $30 \mathrm{ppm}$, respectivamente). No entanto, acredita-se que a redução não tenha sido maior devido aos teores relativamente baixos destes elementos no final do sopro.

De um modo geral, os resultados indicam o post-stirring como uma técnica vantajosa, que possibilita significativa redução de custo e melhoria de qualidade do aço.

\section{REFERÊNCIAS}

I CAMPOS, E. B. Relatório de P\&D: utilização do processo LD-KGC nos convertedores da Usiminas. Ipatinga, 1989.

2 GUY, D.; GROSEJAN, J. C.; LE MAIRE, M. Industrial development of bottom gas injection in top blown converters. In: STEELMAKING CONFERENCE, 63., 1980, Washington, DC. [S.n.t.]. p. 5-I I.

3 BRUCKHAUS, R.; LACHMUND, H. Stirring strategies to meet the highest metallurgical requirements in the BOF process. The Iron \& Steel Technology, v. 4, n. II, p. 44-50, Nov. 2007.

4 ROSE, L.; BECKER, W. Bottom stirring in the converter using the MTBI process. Steel Times International, v. I8, n. 4, p. I8-21, July 1994.

Recebido em: 30/08/20II

Aceito em: $16 / 11 / 2011$ 